\title{
Evaluation of Cutting Properties of a Laser Scalpel with Heavily Absorbing Coatings of an Optical Fiber
}

\author{
DOI: $10.17691 / \mathrm{stm} 2015.7 .3 .07$
}

Received December 10, 2014

V.V. Elagin, Researcher, Laboratory for High-Resolution Microscopy and Gene Technologies,

Institute of Biomedical Technologies'; PhD Student, Department of Biomedicine ${ }^{2}$;

M.A. Shakhova, Tutor, Department of Ear, Nose and Throat Diseases";

M.M. Karabut, Junior Researcher, Laboratory of Study of Optical Structure of Biotissue,

Institute of Biomedical Technologies'; PhD Student, Department of Biophysics²;

D.S. Kuznetsova, Junior Researcher, Laboratory of Regenerative Medicine, Institute of Biomedical Technologies ${ }^{1 ;}$

PhD Student, Department of Biomedicine²;

V.I. Bredikhin, DSc, Leading Researcher, Department of Nanooptics and High Sensitive Optical Measurements ${ }^{3}$;

N.N. Prodanets, PhD, Senior Researcher, Morphology Department, Central Scientific Research Laboratory';

L.B. Snopova, DSc, Head of Morphology Department, Central Scientific Research Laboratory';

O.S. Baskina, PhD, Senior Researcher, Morphology Department, Central Scientific Research Laboratory';

A.V. Shakhov, MD, DSc, Head of the Department of Ear, Nose and Throat Diseases ${ }^{1}$;

V.A. Kamensky, DSc, Leading Researcher, Department of Nanooptics and High Sensitive Optical Measurements ${ }^{3}$

${ }^{1}$ Nizhny Novgorod State Medical Academy, 10/1 Minin and Pozharsky Square, Nizhny Novgorod, 603005,

Russian Federation;

${ }^{2}$ Lobachevsky State University of Nizhni Novgorod, 23 Prospekt Gagarina, Nizhny Novgorod, 603950,

Russian Federation;

${ }^{3}$ Institute of Applied Physics, Russian Academy of Sciences, 46 Ul'yanova St., Nizhny Novgorod, 603950,

Russian Federation

The aim of the investigation was to evaluate the cutting properties of a laser scalpel by applying heavily absorbing coatings (HAC) on an operating silica fiber end.

Materials and Methods. In the investigation we used a laser scalpel with wavelength $0.97 \mu \mathrm{m}$ and output power 3 and $7 \mathrm{~W}$. Tissue was incised by a fiber without coating and coated by a carbon layer or graphite-based HAC.

Results. The assessment of ex vivo tissue incision rate showed a laser scalpel with HAC on a fiber tip to provide maximum cutting rate. Moreover, the mode was characterized by the minimum coagulation area. Incision width is slightly less than that resulted from using a clean fiber end. HAC was more resistant to mechanical and laser action, and persisted on a fiber tip far longer than carbon. In vivo studies on animal skin showed all tissue incision modes to exhibit high coagulability. Histological analysis revealed that laser cutting using a fiber tip having different coatings formed similar tissue structural changes. Skin appeared to have burn destruction of epidermis along the laser exposure width. Derma was found to have visible coagulation morphological changes of the structure. Beneath the coagulation area there were collagen fibers with altered properties: areas with swollen fibers, as well as destruction areas with disruptions and ruptures. HAC application enabled to reduce laser radiation power to provide effective tissue incision.

Key words: laser scalpel; laser radiation; heavily absorbing coatings.

The studies of laser radiation effect on biotissues have been started since the advent of the first lasers. To minimize radiation consequences, a wide range of powerful sources of laser radiation has been developed [1-2]. Structural complexity of biological objects and a great variety of their interactions with light determine the necessity to use in surgery a great number of lasers and laser systems of different types. Currently, laser surgery has come through an investigation phase of exposure modes and become a stable medical technology [3-5].

One of basic elements of a laser scalpel is an optical fiber, which serves as both: a means to delivery radiation to an object, and also an immediate contact with biotissue exercising a scalpel's function. Silica fiber with low attenuation $(20 \mathrm{~dB} / \mathrm{km})$ developed in 1970 by Corning (USA) appeared to be a technological breakthrough. Now fiber-optical waveguide find their application as a transmitting medium in optical communication systems, biosensors and biomedical applications. In laser surgery, multimode silica fibers are used, they transmitting radiation in a wide wavelength range between 300 and $2,400 \mathrm{~nm}$. Generally, a cutting end of a laser scalpel is a fiber core end stripped from a protective layer. Due to a number of characteristics determining their promising application silica fibers are used in laser surgery. The core of such fibers exhibits high strength, though

For contacts: Elagin Vadim Vyacheslavovich, e-mail: elagin.vadim@gmail.com 
maintains mechanical flexibility necessary to position a cutting end. Moreover, it can stand high temperature resulting from biotissue carbonization under laser exposure. Silica fibers are able to transmit high-power radiation. It should be noted that standard mean power of a scalpel is up to several tens of watt.

Various focusing means are used on a fiber end to improve the radiation exposure efficiency [6, 7]. In addition, there are special tips, which enable to control temperature in the exposure area [8]. Optimal parameters for laser modes have been determined for some biotissue types, e.g., cartilaginous tissue. In oncosurgery and cardiosurgery, however, optimal surgical techniques using laser devices are still being searched for, due to what the development of new types of laser scalpels is relevant [9]. A laser resection technique we developed before [10] was based on using a laser source with tunable wavelength and rather high output power (up to $30 \mathrm{~W}$ ). According to the technique, tissues were resected by a clean silica fiber end being in contact with tissue. Biotissue warmed up under laser radiation and was moved apart mechanically by a fiber end. If enough radiation power is used, with time an optic fiber end is contaminated by combustion products resulting in increased radiation absorption, a fiber end heating up to a high temperature. In this case biotissue is exposed to a combined effect of laser radiation and a hot optic fiber end.

The techniques suggested by other authors are based on using laser radiation with wavelengths highly absorbable by biotissues, generally, due to water or hemoglobin contained in tissue [11]. The modification we offer is based on specific heavily absorbing coatings (HAC) applied on a fiber end, HAC consisting of a mixture of graphite powder and silicone varnish. Graphite is characterized by a high absorption coefficient in a wide spectral band, and has high thermostability. Silicone varnish provides a stable bond between graphite and an optical fiber (silica).

The present study represents the first results of HAC application enabling to obtain unified exposure modes for lasers with various wavelengths, silica fiber being the means to deliver radiation to a targeted object.

Materials and Methods. The experiments were carried out using a laser scalpel LSP-0.97/10 (Azor, Russia) with continuous laser operation at wavelength of $970 \mathrm{~nm}$. Silica fibers, $550 \mu \mathrm{m}$ in diameter, were used to delivery radiation to tissues. We preliminarily evaluated the cutting capability of the scalpel ex vivo on chicken muscular tissue. Three tissue cutting modes were studied:

1) with a clean operating fiber end;

2) with an end initiated by a carbon layer;

3) with an end initiated by a liquid HAC.

In carbon layer initiation we used special carboncontaining tablets (Dental Photonics, Inc., USA) in accordance with the manufacturer technique [11]. We also used HAC we developed: a mixture of graphite powder, its fraction sizes being under $0.5 \mu \mathrm{m}(5-20 \%)$, and polymethyl phenyl-silane resin-based (80-95\%) silicone varnish. The fiber end initiation technique was similar to that of Dental Photonics, Inc. slightly changed: a mixture droplet was applied on glass surface, an operating fiber end being dipped in it. A laser source with power of $0.5-1.0 \mathrm{~W}$ was switched on for a period of time up to $1 \mathrm{~min}$ to dry the applied layer. For a thicker layer the procedure was to be repeated.

For incision unification we fabricated an device that enables to pass a fiber end along a biotissue by equal force $0.44 \mathrm{H}(45 \mathrm{~g})$. The device includes the base and a vertical guide with a movable fiber carriage mounted. An operating fiber end fastened horizontally was led to biotissue surface followed by a linear incision made under gravity. Cutting capability of a laser scalpel was assessed by the following parameters:

1) tissue cutting rate;

2) width of an incision obtained;

3) incision depth;

4) coagulation area width;

5) the presence of tissue carbonization in the incision.

The matched modes were tested on male nonlinear white rat skin. Beforehand, the animal hair had been removed on the intended area exposed to laser radiation. Then an animal was anesthetized with $50 \mathrm{mg} / \mathrm{kg}$ of Zoletil. Tissue was incised by a laser scalpel using several operating modes:

1) with a clean fiber end and output power of $3 \mathrm{~W}$;

2) with a clean fiber end and output power of $7 \mathrm{~W}$;

3) with a modified HAC fiber end and output power of $3 \mathrm{~W}$;

4) with a modified carbon fiber end and output power of $3 \mathrm{~W}$.

Incision was followed by recording a skin lesion using USB-microscope Micmed 2000 R (China) and its assessment according to the five parameters above mentioned. After the procedure the samples were histologically examined. For this purpose skin fragments were incised out of the exposure area, fixed in $10 \%$ neutral formalin, dehydrated in high-proof alcohol and embedded in paraffin. Histological sections, 5-7 $\mu \mathrm{m}$ thick, were made by a microtome Leica SM 2000 (Germany) so that the tissue sections were perpendicular to the laser scalpel direction. To assess the condition of collagen fibers in derma, they were van Gieson's stained. We used a light microscope Leica DM 1000 (Germany) to study skin structural damage in the laser exposure area, images was acquired by a digital camera Leica DFC 290 (Germany).

\section{Results}

Contact treatment of laser radiation by a silica fiber end on ex vivo samples with controlled force. A preliminary ex vivo study on chicken muscular tissue samples showed the incision rate to be $4 \mathrm{~mm} / \mathrm{min}$, when using a clean operating fiber end, the output power 
being $3 \mathrm{~W}$. Incision depth was $1 \mathrm{~mm}$. Coagulation area, $2.0 \mathrm{~mm}$ wide, formed around the incision. No tissue carbonization was found. The power increase up to $4 \mathrm{~W}$ resulted in tissue cutting rate growth up to $11.4 \mathrm{~mm} / \mathrm{min}$, the coagulation area width decreasing to $1.1-1.3 \mathrm{~mm}$. In addition, the incision depth increased to $2.5 \mathrm{~mm}$, there appearing tissue carbonization. Biotissue incised by a laser scalpel with output power $7 \mathrm{~W}$ was $2.0 \mathrm{~mm}$ wide and $2.0 \mathrm{~mm}$ deep. Coagulation zone was $6.8 \mathrm{~mm}$, the incision rate being $22 \mathrm{~mm} / \mathrm{min}$.

An optical fiber with HAC applied on its end and output power $2 \mathrm{~W}$ enabled to incise the tissue, $1.2 \mathrm{~mm}$ wide and $1.3 \mathrm{~mm}$-coagulation area. The depth of such incision varied from 1.5 to $2.0 \mathrm{~mm}$. The cutting rate of the mode was $11 \mathrm{~mm} / \mathrm{min}$. If output power grew to $3 \mathrm{~W}$, the cutting rate increased up to $30 \mathrm{~mm} / \mathrm{min}$. Coagulation area width increased slightly, up to $1.5 \mathrm{~mm}$.

An optical fiber with an operating carbon-coated end was characterized by higher incision rate. If output power was $2 \mathrm{~W}$, the cutting rate was $9.9 \mathrm{~mm} / \mathrm{min}$, the output power being $3 \mathrm{~W}$, the rate reached $16.2 \mathrm{~mm} / \mathrm{min}$. The width of incision and coagulation area at $2 \mathrm{~W}$ was $1.7 \mathrm{~mm}$ and $1.8 \mathrm{~mm}$, respectively; the cutting depth being $3.0 \mathrm{~mm}$. The increased power, up to $3 \mathrm{~W}$, resulted in increased incision width, up to $2.0 \mathrm{~mm}$, coagulation area width reducing up to $1.3 \mathrm{~mm}$. The incision depth remained unchanged.

Contact treatment of laser radiation by a silica fiber end on rat skin. When incising in vivo tissues we found all the modes used to have high coagulability. There were none hemorrhage cases. Moreover, all modes under study appeared to result in the formation of tissue carbonization area. The depth of forming incisions was independent of a mode type and was about $1 \mathrm{~mm}$, while the incision width varied. The incisions made by a clean operating fiber end were characterized by the narrowest width. If output power was $3 \mathrm{~W}$, the width was $1.1 \mathrm{~mm}$, $7 \mathrm{~W}$ output power resulted in the incisions $1.3 \mathrm{~mm}$ wide. HLC applied on a fiber end of a laser scalpel led to the increase in incision width up to $1.5 \mathrm{~mm}$, the output power of a scalpel being $3 \mathrm{~W}$, while a carbon-coated fiber end resulted in an incision $2.2 \mathrm{~mm}$ wide at the same output power.

A fiber end with HAC applied succeeded in tissue incision more easily and at higher rate. Moreover, HAC was more resistant to mechanical and laser action. For example, if carbon coating completely disappeared after a 5 min contact of a fiber end with biotissue, HAC was effective for about $15 \mathrm{~min}$.

Microscopic study of skin samples at the exposure site resulted from different laser fiber types revealed tissue structural changes typical for thermal damage.

The incision made by a clean fiber end at $3 \mathrm{~W}$ power resulted in carbonization and desquamation of epithelial layer. Derma tissue in a subepithelial layer was coagulated and thickened, with tinctorial properties impaired (fuchsinophilia attenuation). Collagen fiber structure was not determined, cells and nuclei being destroyed. III-defined derma underlay the dense area, the derma preserving its structural signs, swollen and homogenized collagen fibers. Moreover, there was normal staining of collagen by fuchsin.

In vascular lumens red blood cell hemolysis was observed. In addition, there were the signs of fluid loss in tissues exposed to laser radiation, evidently due to high temperature. The signs were in the form of derma tissue rarefaction and exfoliation of connective tissue components around hair follicles. The defect width along the sample surface was $1,989 \mu \mathrm{m}$, its depth including coagulation zone and the area with swollen and homogenized collagen fibers being from 267 to $486 \mu \mathrm{m}$ (See the Figure (a)).

Skin surface exposed to laser radiation with output power of $7 \mathrm{~W}$ by a clean fiber end appeared to have carbonization and desquamation of epithelial layer. The surface derma layer also had the signs of tissue carbonization, this layer having cell structure. Coagulation zone with complete loss of tissuespecificity extended deeper compared to that resulted from the laser exposure with power of $3 \mathrm{~W}$, and was denser. The swelling and homogenization signs of collagen fibers were found deep into tissue. Impaired structure due to thermal action was also revealed in subcutaneous fat in the form of cell destroy, collagen fiber fragmentation and separation. Dehydration of tissues surrounding the defect was more pronounced compared to that resulted from the exposure of a laser with a clean operating end, its power being $3 \mathrm{~W}$. The defect width along the sample surface was $1,700 \mu \mathrm{m}$, total depth including carbonization area being $80 \mu \mathrm{m}$, the depth of coagulation changes being $638 \mu \mathrm{m}$, and the area with swollen and homogenized collagen fibers being $1,170 \mu \mathrm{m}$ deep.

After laser cutting using an optical fiber with HAC applied on its end, epithelial carbonization persisted on the exposure area, the carbonization area merging with the area of coagulation changes. The latter was less prominent compared to the similar one after incision made by a clean operating fiber end. On the other hand, the defects in the underlying area in the form of swelling and homogenization of collagen fibers were more prominent, the area itself being clearly outlined against the surrounding structures. Tissue dehydration signs were clearly observed: there was tissue disruption down to muscular tissue. The laser exposure surface area was 2,210 $\mu \mathrm{m}$ wide, its total depth being $663 \mu \mathrm{m}$, carbonization area being $44 \mu \mathrm{m}$, coagulation area varying from 221 to $266 \mu \mathrm{m}$ (See the Figure (b)).

Incisions made by an optical fiber with a carbon layer applied were characterized by carbonization of epidermis and its keratolysis. The area of coagulation changes in the area adjacent to epidermis had cellular structure, the zone steadily changing into shallow derma preserving its structural features, however, it having swelling and 

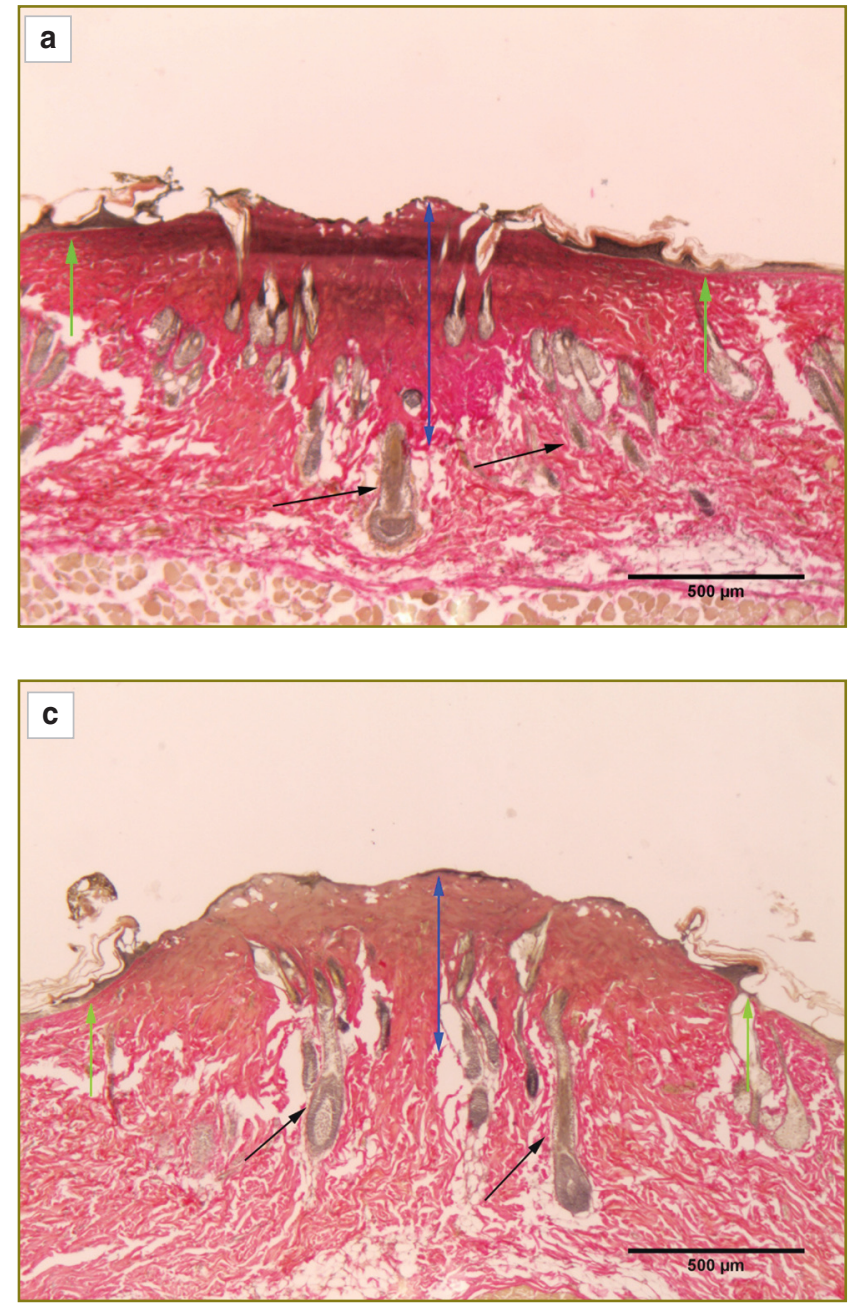

homogenization of collagen fibers. In addition, there was normal staining of collagen by fuchsin. No marked dehydration signs of surrounding tissues were found. The width of damaged tissue along the sample surface was $1,503 \mu \mathrm{m}$, total depth of exposure area was $399 \mu \mathrm{m}$, coagulation zone being from 177 to $239 \mu \mathrm{m}$ (See the Figure (c)).

Histological analysis showed similar lesions to form regardless the type of a fiber end used: a clean fiber end or a coated one. However, HAC fiber ends produce deeper incisions compared to those made by a clean fiber end, or a carbon-coated end. It can reduce the number of scalpel passes and speed up the cutting process.

Conclusion. Heavily absorbing coatings applied on an operating optical fiber end enable to optimize tissue cutting modes due to the reduction of laser radiation output power. Graphite and silicone varnish-based heavily absorbing coatings provide higher tissue cutting rate compared to that achieved when using a clean end or a carbon modified end. The coating preserves on the fiber end significantly longer compared to that with

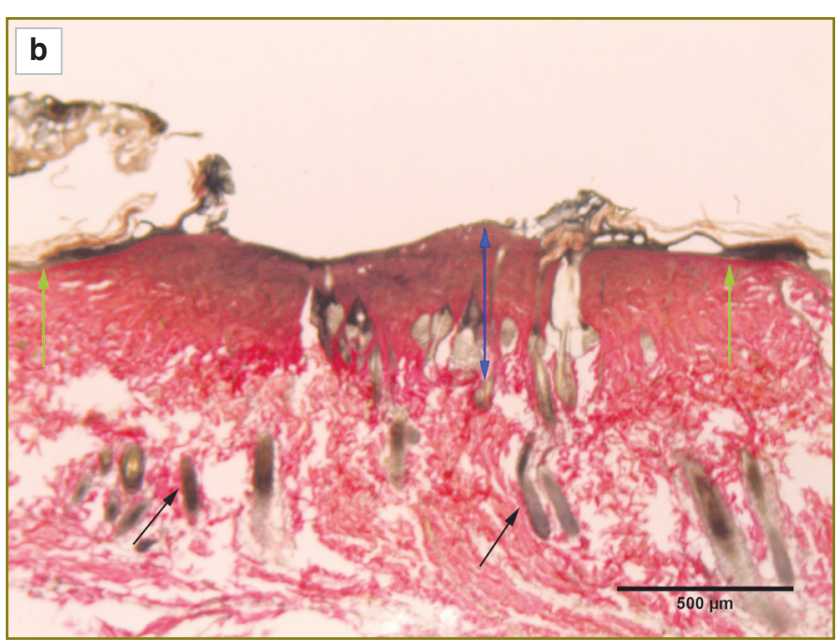

A histological image of rat skin after the contact of a quartz optical fiber having a clean end (a), with heavily absorbing coating applied (b) and a carbon-coated end (c). Van Gieson's stain. Blue arrows indicate the lesion width, green arrows indicate the lesion depth, and black arrows indicate hair follicle

a carbon-coated end. The initiation of fiber end surface coatings of a laser scalpel enables to optimize the modes of laser radiation exposure to biotissue.

Study Funding. The study was funded by a grant of Russian Science Foundation "The Use of Laser Induced Nonequilibrium Processes in Medical Technologies" No.14-15-00840 dated May, 20, 2014.

Conflicts of Interest. The authors have no conflicts of interest related to the present study.

\section{References}

1. Steiner R. Laser-tissue interactions. In: Laser and IPL technology in dermatology and aesthetic medicine. Edited by Raulin C. and Karsai S. Springer-Verlag Berlin Heidelberg; 2011, http://dx.doi.org/10.1007/978-3-642-03438-1_2.

2. Tuchin V.V. Lazery $i$ volokonnaya optika $v$ biomeditsinskikh issledovaniyakh [Lasers and fiber optics in biomedical research]. Moscow: FIZMALIT; 2010; 488 p.

3. Skobelkin O.K. Lazery $v$ khirurgii [Lasers in surgery]. Moscow: Meditsina; 1989; 256 p.

4. Lazernaya inzheneriya khryashchey [Laser engineering for cartilage]. Pod red. Bagratashvili V.N., Sobolya E.N., 
Shekhtera A.B. [Bagratashvili V.N., Sobol' E.N., Shekhter A.B. (editors)]. Moscow: FIZMATLIT; 2006; 342 p.

5. Lasers for medical applications: diagnostics, therapy, and surgery. Edited by Jelinkova H. Woodhead: Oxford, UK; 2013; p. 832.

6. Belikov A.V., Skripnik A.V. Lazernye biomeditsinskie tekhnologii [Laser biomedical technologies]. Saint Petersburg: SPbGU ITMO; 2009; 100 p.

7. Stock K., Stegmayer T., Graser R., Förster W., Hibst R. Comparison of different focusing fiber tips for improved oral diode laser surgery. Lasers Surg Med 2012; 44(10): 815-823, http://dx.doi.org/10.1002/lsm.22091.
8. Asah B., Balle-Petersen O., Dolleris C. Apparatus for tissue treatment. US 6533776 B2. 2003.

9. Freebody M. Fiber lasers at the cutting edge of surgery. Biophotonics 2013; 20(3), URL: http://www.photonics.com/Article. aspx?PID=1\&VID=108\&IID=681\&Tag=Features\&AID=53575.

10. Shakhov A.V., Terentjeva A.B., Kamensky V.A., Snopova L.B., Gelikonov V.M., Feldchtein F.I., Sergeev A.M. Optical coherence tomography monitoring for laser surgery of laryngeal carcinoma. J Surg Oncol 2001; 77(4): 253-258, http:// dx.doi.org/10.1002/jso.1105.

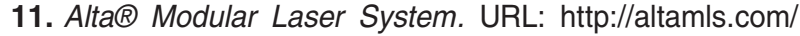
applications/soft-tissue-surgery/how-top-surgery-works/. 